\title{
Prospective study of urinary tract infection surveillance after kidney transplantation
}

\author{
Roberto Rivera-Sanchez ${ }^{1}$, Dolores Delgado-Ochoa², Rocio R Flores-Paz', Elvia E García-Jiménez ${ }^{1}$ \\ Ramon Espinosa-Hernández ${ }^{3}$, Andres A Bazan-Borges ${ }^{3}$, Myriam Arriaga-Alba ${ }^{1,4^{*}}$
}

\begin{abstract}
Background: Urinary tract infection (UTI) remains one of the main complications after kidney transplantation and it has serious consequences.

Methods: Fifty-two patients with kidney transplantation were evaluated for UTI at 3-145 days (mean 40.0 days) after surgery.. Forty-two received a graft from a live donor and 10 from a deceased donor. There were 22 female and 30 male patients, aged 11-47 years. Microscopic examinations, leukocyte esterase stick, and urinary culture were performed every third day and weekly after hospitalization. A positive culture was consider when patients presented bacterial counts up to $10^{5}$ counts.

Results: UTI developed in 19/52 (37\%) patients at 3-75 days (mean 19.5 days after transplantation. Recurrent infection was observed in 7/52 (13.4\%) patients at days 17-65. UTI was more frequent in patients who received deceased grafts compared with live grafts $(7 / 10,70 \%$ vs. 12/42, 28\%; $p<0.007)$. Female patients were more susceptible than male $(11 / 22,50 \%$ vs. 8/22, 36.35\%; $p<0.042)$. Five-year survival rate was $94.5 \%$ (49/52 patients). Kidney Graft exit update is $47 / 52(90.2 \%)$, and there were no significant differences between graft rejection and UTI ( $p=0.2518)$. Isolated bacteria were Escherichia coli (31.5\%), Candida albicans (21.0\%) and Enterococcus spp. (10.5\%), followed by Pseudomonas aeruginosa, Klebsiella pneumoniae, Morganella morganii, Enterobacter cloacae and Micrococcus spp. Secondary infections were produced by (7/19, 36.8\%). Enterococcus spp. (57\%), E. coli (28\%) and Micrococcus spp. (14.2\%). Antibiotic resistance was 22\% for ciprofloxacin and 33\% for ampicillin. Therapeutic alternatives were aztreonam, trimethoprim-sulfamethoxazole, netilmicin and fosfomycin.

Conclusions: Surveillance of UTI for the first 3 months is a good option for improving quality of life of kidney transplantation patients and the exit of graft function especially for female patients and those receiving deceased grafts. Antibiograms provided a good therapeutic alternative to patients who presented with UTIs after receiving a kidney allograft.
\end{abstract}

\section{Background}

Treatment for patients with severe renal failure has been improved, especially with better surgical procedures and pharmaceutical management. Nevertheless, since these patients require immunosuppressive therapy, they are vulnerable to developing postoperative infections. Among these, urinary tract infections (UTI) are the most frequently observed and have high morbidity $[1-3,5,6]$. UTI was observed in $54.2 \%$ of 149 patients in Iran [7]. The frequency of UTI has varied between

\footnotetext{
* Correspondence: arriaga_alba@yahoo.com

'Microbiology Research Laboratory, Hospital Juárez de México, Avenida Instituto Politécnico Nacional, México, D.F. 07760, México

Full list of author information is available at the end of the article
}

studies. A study in Tunisia has reported a UTI incidence of $43 \%$ within the first month and $33 \%$ for up to 6 months [8].[ In France, Pellé et al [9] have reported UTI in $77 \%$ of 177 patients who had undergone kidney transplantation. UTI after kidney transplantation has been associated with patient mortality and graft failure [10]. Nampoory et al [11] have recommended surveillance for UTI for a period of 6 months, to diminish the risk of renal failure. Charfeddine et al. [8] have reported that UTI was observed in all patients with graft rejection and $58 \%$ of patients without rejection.. Akinalow et al [12] have described UTI as an important risk factor for mortality in kidney transplantation patients.

\section{() Biomed Central}


Cytomegalovirus infections have been well documented as an important cause of graft rejection [7], therefore, recipients always receive antiviral therapy, before and after surgery for prophylaxis. In addition, bacterial infections have high morbidity and mortality and should not be discounted [7]. Several species of bacteria that cause UTI in kidney transplant patients have been isolated. Escherichia coli has been reported as the main uropathogen isolated in UTI among transplant patients in studies in Spain, India and Kuwait [11,13-15]. Klebsiella spp., Pseudomonas spp., including $P$. aeruginosa, and multiresistant isolates of E. coli, may by important etiological agents of these infections Gram-positive bacteria may also be important etiological agents of UTI, and the most frequently isolated have been Enterocooccus spp. and Staphylococcus aureus [4,11,14-17]. Less frequently, Corynebacterium urealyticum is considered as an etiological agent.

Infections caused by Candida spp. may be a serious problem in transplant recipients. They might cause infections of the bloodstream that can lead to sepsis. Such infection is caused frequently by catheter colonization and is improved with catheter removal. Candida albicans must be diagnosed rapidly because it may have fatal consequences $[18,19]$.

Urinary culture, with microscopic examination and leukocyte esterase stick, has been recommended as a good predictor of symptomatic UTI [20]. Urinary culture in kidney transplant patients has been questionable, as a result of its cost, and it may be replaced with microscopic examination and the leukocyte esterase stick. Nevertheless, it is advisable to carry out urinary culture on kidney transplant patients within the first few months, because of their extreme vulnerability to UTI. Furthermore, urinary culture gives the opportunity of performing an antibiogram, which can lead to appropriate medical treatment. In fact, appropriate antibiotic therapy might give the patients a greater probability of preserving graft function $[21,22]$.

This study aimed to establish the frequency of UTI in kidney transplant patients at Hospital Juárez de México, evaluate the greatest risk factors for developing UTI, and offer the physician and patient a good diagnosis and appropriate antibiotic therapy.

\section{Methods \\ Study design}

This was a prospective, clinical, noninvasive study. Fiftytwo patients who underwent kidney transplantation at Hospital Juárez of México between November 1999 and October 2001 were included. Forty-two patients (22 female, 10 male, aged 11-47 years) received a graft from a living related donor and 10 from a deceased donor. A Foley catheter was installed before surgery, and it remains from 10 to 14 days afterwards. After surgery patients received an immunosuppressive treatment with prednisone, cyclosporine and azatioprine. All patients take as prophylactic treatment cefalosporine 2 generation $1.5 \mathrm{~g} /$ day for 10 days, aciclovir $400 \mathrm{mg}$ and nitastatine $100000 \mathrm{u}$ each six hours for three months. Urinary samples were recovered directly from the catheter at 2448 hours after surgery, and then every third day throughout the hospitalization period. Afterwards, patients were given sterile material and invited to take first morning sterile urine sample to the microbiology research laboratory each then days, when attending the Hospital for its usual medical control or cyclosporine detection levels at the HLA research laboratory.

\section{Ethical considerations}

This study commenced following approval of the Research and Ethical Committees of the Hospital Juárez of México. Consent letters were not necessary because this study did not involve any invasive procedures for the patients. Patients were informed orally about the study and voluntary participation was offered after treatment of UTIs. The required sterile specimens were provided by the microbiology research laboratory and the cultures did not incur any financial costs for the patients.

\section{Urinary studies}

Qualitative urinary cultures were done on blood agar, MacConkey agar and Biggy agar. as described previously [20] Cultures were incubated at $37^{\circ} \mathrm{C}$ for 24 hours. BiGGY plates were incubated for 72 hours. Urinary samples were evaluated with the leukocyte esterase stick, using Multistix 10 SG reagent strips (Bayer Diagnostics, S.A. de C.V., México, D.F.). Microscopic urinary sediment examinations were done after centrifugation of the sample at $1000 \mathrm{~g}$ for 15 minutes on a clinical centrifuge (Clay Adams Dynac, Beckton Dickinson Co.).[Parsippant N.J. 07054] Epithelial cells, urinary crystals and the number of leukocytes per microscopic field were recorded [20]. Urinary studies were performed every third day and weekly after hospital discharge. It was considered a positive result for Urinary tract infection [UTI], when bacterial counts were recorded up to $10^{-5}$ counts, and leukocytes were up to 10 per microscopic field. Positive nitrates value was recorded for Gram negative bacteria. Lower bacterial counts were considered as bacteriuria, and they were not considered for the purpose of this study

\section{Susceptibility studies}

Positive urinary cultures were processed for antimicrobial susceptibility testing on Mueller-Hinton agar plates, using the Kirby-Bauer disk diffusion method, according 
to the NCCLS specifications. Gram-negative bacteria were evaluated against ciprofloxacin, aztreonam, ampicillin, gentamicin, cefoperazone, arbenicillin, kanamycin, tetracycline, norfloxacin, aztreonam, trimethoprim-sulfamethoxazole, netilmicin and fosfomicin. Enterococcus spp. were evaluated against ampicillin, cefotaxime, penicillin, erythromycin, ceftriaxone, trimethoprim-sulfamethoxazole, and vancomycin. Susceptibility tests were performed employing commercial Sensi-Discs from BDBBL, Becton Dickson Company Sparks, MD 21152, USA.

\section{Statistical analysis}

Studies were evaluated with the $X^{2}$ test. Statistical analysis was performed with Graph-Pad version 2.01 software.

\section{Results}

\section{Patient surveillance}

Patients were evaluated for UTI from 3 to 150 days (mean $40.75 \pm 40.0$, arithmetic mode 40 days) after surgery. Four patients could not continue their evaluation beyond the first period as they lived outside Mexico City Other patients, continued voluntarily with microbiological evaluation for up to 3 months.

\section{UTI}

UTIs were recorded in 19/52 (37\%) patients. UTI was present as early as day 3 and as late as day 75, with a mean of 19.5 days. Reinfection was observed in 7/19 (36.8\%) patients with previous UTI, from day 17 to 65. These infections were more frequent among patients who received a deceased graft compared with a graft from a live donor, as it is shown on Figure 1. Female patients were more susceptible to UTI than male patients $(11 / 22,50 \%$ vs. $8 / 30,22 \%$; $\mathrm{p}=0.045)$. Fortynine of 52 patients $(94.5 \%)$ survived for up to 5 years. The graft exit monitoring up to 7 is descrived on (Table 1). Rejetion within UTI or not UTI, was higher,

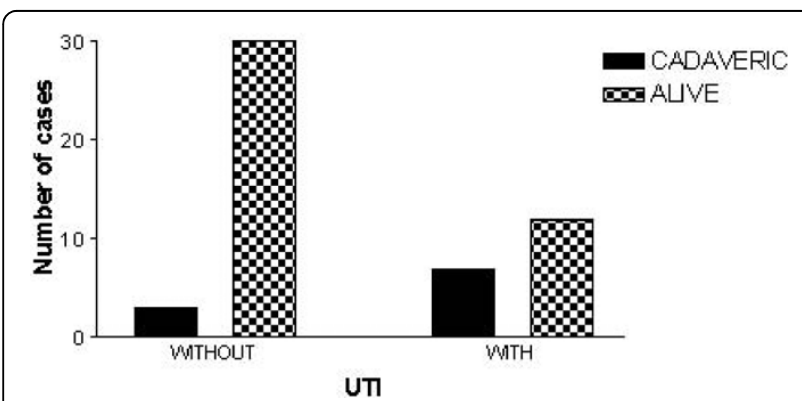

Figure 1 Urinary tract infections with cadaveric or living donors. Frequency of UTI among patients who received a deceased or live donor grafts. $p=0.007$ ( $X^{2}$ test) but these results were not statistically significant $(\mathrm{p}=0.2518)($ Table 2$)$.

\section{Microbiological results}

The first infections developed were caused mainly by E. coli, C. Albicans, Enterocoocus spp., and Enterobacteriaceae (Table 3). The secondary infections were caused mainly by Enterococcus spp. $(3 / 7,47 \%)$, E. coli $(2 / 7$, $28.5 \%)$ and Micrococcus spp. (1/7, 14.28\%).

\section{Antimicrobial agents}

The most recommended antibiotics for kidney transplant patients were ciprofloxacin and ampicillin. Ciprofloxacin resistance was observed among $22 \%$ of isolated strains, and ampicillin resistance among $33 \%$ of the isolated Gram-negative bacteria. Therapeutic alternatives for these cases were aztreonam, trimethoprim-sulfamethoxazole, netilmicin and fosfomycin. A multiresistant Enterococcus was recovered, which was sensitive only to vancomycin.

\section{Discussion}

This work demonstrated that, despite prophylactic treatment of kidney transplant patients, UTI was a major postoperative complication. Nineteen of 52 patients (37\%) developed at least one episode of UTI. These results are similar to those of Kanisauskaite et al [23], who reported UTI in $37 \%$ of 57 patients, and Memikoglu [4], who found UTI in $41 \%$ of 136 patients in Turkey. However, these numbers of patients are lower than those reported by Poumard et al [7], who found UTI in $54 \%$ of 179 patients in Iran. These works state up the need of including studies of infectious diseases besides the renal function tests after kidney transplantation.

In the present study, we found that patients who received a deceased graft were more susceptible to UTI, compared with a graft from a living related donor $(70 \%$ vs. $28 \%$ ), and may reflect an asymptomatic infection in the cadaver donor which developed in the immunosuppressed patient; in contrast, live donors are evaluated carefully before surgery. Similar results have been reported by Midtvedt et al [24], who reported that deceased kidney recipients had higher rates of infections. In the present study, female sex was found to be a risk factor for UTI, as reported previously [4].

It has been proposed that surveillance of UTI in kidney transplant patients should be performed over a long period. Kumar et al [21] have suggested evaluation over the first 100 days, and Dupont et al [25] have reported that late UTI may damage renal allografts at more than a year after surgery. We found UTI between 3 and 75 days after surgery, therefore, we confirm that surveillance should be carried out for 3 months after kidney transplantation. 
Table 1 Characteristics of patients with renal allograft

\begin{tabular}{llll}
\hline Characteristics of the evaluated group & Number of cases & Percentage & Significant $\boldsymbol{X}^{\mathbf{2}}$ test \\
\hline Women with UTI & $11[22]$ & $50 \%$ & $\mathrm{p}=0.042$ \\
Men with UTI & $8[30]$ & $22 \%$ & $\mathrm{p}=0.007$ \\
Deceased donor with UTI & $7[10]$ & $70 \%$ & N.S. p $=0.46$ \\
Alive donor with UTI & $12[42]$ & $28 \%$ & \\
Rejection with UTI & $3[33]$ & $9 \%$ & $10.5 \%$ \\
Rejection without UTI & $2[19]$ & $94.23 \%$ & \\
Patient survival after 5 years & $49[52]$ & $90.38 \%$ & \\
Graft function survival to present day & $47[52]$ & $0 \%$ & \\
Death and UTI & $0[5]$ & &
\end{tabular}

Our patients have continued to the present day with evaluation of cyclosporine levels at the HLA research laboratory, as well as medical evaluation. The 5-year survival was $94.5 \%$ ( $49 / 52$ patients), and 47 patients have survived to the present. The graft exit up to seven years was $47 / 52$ [90.2\%]. This result is higher than that reported by Kanisauskaite et al [23] in Lithuania, who had $85 \%$ of kidney survival exit.

In our patients, E. coli was the main agent that caused UTI after kidney transplantation,[table 3] and the infective agent in one of the three patients who suffered kidney allograft rejection, which is similar to several other studies from around the world $[4,11,14,15,19]$. The second major cause of infection in our patients was C. albicans, which was cultured from four patients, two of whom developed reinfection with Enterococcus spp. and E. coli. C. albicans infection in our patients was more common than that observed by Valera et al in Spain [15]. Candida infection can have serious consequences if it is not detected early. Catheter removal and amphotericin B is a good therapeutic option for these patients [18]. Unfortunately, one of the four patients infected with Candida spp. suffered graft rejection before day 10 .

$S$. aureus is one of the most important microorganisms that causes UTI in transplant patients but it was not observed in the present study [26,27]. Among the Gram-positive bacteria, the main organism observed in our study was D enterococci, both in primary and secondary infections. One of the patients infected with this bacterium suffered allograft rejection before day 10 . These results are in agreement with previously published studies. Alangaden [13] and Leigh et al. [26], have designated Enterococcus spp. as an emerging bacterium

Table 2 Patients with UTI and kidney allograft loss

\begin{tabular}{lccc}
\hline & $\begin{array}{c}\text { Allograft survival to } \\
\text { present }\end{array}$ & $\begin{array}{c}\text { Allograft } \\
\text { rejection. }\end{array}$ & (\%) \\
\hline With UTI & 14 & 3 & $21.0 \%$ \\
\hline $\begin{array}{l}\text { Without } \\
\text { UTI }\end{array}$ & 33 & 2 & $6.06 \%$ \\
\hline$x^{2}$ test: NS. P =0.1709 & & & \\
\hline
\end{tabular}

that causes symptomatic infections, especially in kidney transplant patients.

The cost-benefit of urinary cultures has been questioned, especially in asymptomatic UTI in kidney transplant patients [28]. It is thus advisable to conduct additional studies to evaluate the advantages of performing cultures in all post-transplant patients for UTI surveillance.

In contrast, it has been reported that multiresistant bacteria might be cultured from kidney transplant patients as a consequence of prophylactic therapy, therefore antibiograms of the infecting microorganisms have been suggested $[1,3,16]$. Antibiograms were performed for infective bacteria in our study, in order to offer more appropriate therapy to patients. Antibiograms in these patients are useful to reduce employment of antibiotic therapy on unnecessary cases and to improve antibiotic therapy on kidney transplanted patients. Twenty-two percent of our isolates were resistant to ciprofloxacin, which is used widely in kidney transplant patients, although this was lower than the $50 \%$ resistance reported by Senger et al. in 2007 [3]. In the present study, ampicillin resistance was observed in $33 \%$ of the Gram-negative strains. The main therapeutic options

Table 3 Isolated microorganisms from UTI from kidney transplant patients

\begin{tabular}{lcc}
\hline Isolated strains & No. of cases & Frequency (\%) \\
\hline E. coli & 6 & 31.579 \\
\hline Candida spp. & 4 & 21.053 \\
\hline Enterococcus spp. & 2 & 10.526 \\
\hline A. calcoaceticus var. Anithratus & 1 & 5.263 \\
\hline E. cloacae & 1 & 5.263 \\
\hline K. oxytoca. & 1 & 5.263 \\
\hline K. pneumoniae & 1 & 5.263 \\
\hline M. morganii & 1 & 5.263 \\
\hline P. aeruginosa & 1 & 5.263 \\
\hline Micrococcus spp. & 1 & 5.263 \\
\hline Total & 19 & 100.000 \\
\hline
\end{tabular}


were aztreonam, trimethoprim-sulfamethoxazole, netilmicin and fosfomycin. Cephalosporin showed intermediate resistance in our study, whereas, Lazinzka et al [29] reported that $90 \%$ of Gram-negative strains isolated from kidney transplant patients in Poland were susceptible to ceftriaxone and ceftazidime. These result might explain the failure of the employed prophylaxis in patients developing UTI. In fact, it is known that antibiotic resistance is a frequent medical problem due to the injudicious use of these drugs; however an individual antibiogram, as obtained in this study, gave a good therapeutic alternative to patients who presented with UTI after receiving a kidney allograft.

Surveillance of UTI in the first 3 months after surgery, using urinary culture, leukocyte esterase stick and antibiograms, is a good way to reduce the risk of UTI in transplant patients and the exit of the graft function, especially those receiving deceased grafts or female patients. In the present study, $3 / 19$ patients with UTI suffered kidney graft rejection, while only $2 / 33$ patients without UTI had graft rejection. This difference was not statistically significant, which differs from previous studies that have stated that UTI might be a cause of graft rejection [30]. Nevertheless, it may be worthwhile to advise patients to continue with their clinical and bacteriological evaluation after surgery.

\section{Conclusions}

Surveillance of UTIs for the first 3 months is a reasonable option for improving graft function free of kidney infections and assuring the quality of life for the kidney transplant population and the loss of graft function, especially for female patients and those receiving suspicious deceased grafts. Antibiograms give a good therapeutic alternative to patients who present with UTIs after receiving a kidney allograft.

\section{Acknowledgements}

We thank L.E. Concepción Gonzalez Juárez for taking patients urinary samples.

\section{Author details \\ 'Microbiology Research Laboratory, Hospital Juárez de México, Avenida Instituto Politécnico Nacional, México, D.F. 07760, México. ${ }^{2}$ Histocompatibility Research Laboratory, Hospital Juárez de México, Avenida Instituto Politécnico Nacional, México, D.F. 07760, México. ${ }^{3}$ Renal Transplant Surgery Division. Hospital Juárez de México, Avenida Instituto Politécnico Nacional, México, D. F. 07760, México. ${ }^{4}$ Hospital Juarez De Mexico. Avenida Instituto Politécnico Nacional No. 5160, DF., 07760, México.}

\section{Authors' contributions}

RRS carried out the bacteriological studies and antibiograms; DDO performed cyclosporine surveillance and post-hospital interviews; RFP and EGJ performed the urinary cultures and microscopic examinations; $A B B$ and REH carried out the kidney transplant surgery; REH has revised the manuscript. MAA designed the study, performed the statistical analysis and prepared the manuscript. All authors read and approved the final manuscript.

\section{Competing interests}

All of the authors confirm that do not have any competing interests or financial gain or commercial compromise based on the work in this investigation.

Received: 24 June 2009 Accepted: 19 August 2010

Published: 19 August 2010

\section{References}

1. Ahamad E, Malek Hosseini SA, Salahi H, Javid R, Ghaharamani N, Nezakatgoo N: Experience with 300 renal transplant in Shiraz, Iran. Transplant Proc 1995, 27(5):2767.

2. Reissi D, Bardideh A, Samadzadeh B, Razi A: Kidney transplantation in Kermnshah Iran: a 5 years experience. Transplant Proc 1995, 27:2765-2766.

3. Senger SS, Arslan H, Azap OK, Timurkaynak F, Cağir U, Haberal M: Urinary tract infections in renal transplant recipients. Transplant Proc 2007, 39:1016-1017.

4. Memikoğlu KO, Keven K, Sengül S, Soypaçaci Z, Ertürk S, Erbay B: Urinary tract infections following renal transplantation: a single-center experience. Transplant Proc 2007, 39:3131-3134.

5. Shaheen FA, Basri N, Mohammed Z, Abdullah K, Haider R, Awad A, Nasser A, El Gabarty A: Experience of renal transplantation at the King Fahd hospital, Jeddah, Saudi Arabia. Saudi J Kidney Dis Transplant 2005, 16(4):562-572.

6. De Souza RM, Olsburgh J: Urinary tract infection in the renal transplant patient. Nat Clin Pract Nephrol 2008, 4:252-264

7. Poumard G, Salem S, Mehrsai A, Taherimahmoudi M, Ebrahimi R, Pourmand MR: Infectious complications after kidney transplantation: a single-center experience. Transplant Infect Dis 2007, 9:302-309.

8. Charfeddine K, Kharrat M, Yaich S, Jarraya F, Mkawar K, Hachicha J: Infection in Kidney transplant recipients in Tunisia. Saudi J Kidney Dis Transplant 2002, 13(2):195-198.

9. Pellé G, Vimont S, Levy PP, Hertig A, Ouali N, Chassin C, Arlet G, Rondeau E, Vandewalle $A$ : Acute pyelonephritis represents a risk factor impairing long-term kidney graft function. Am J Transplant 2007, 7:899-907.

10. John U, Everding AS, Kuwertz-Bröking E, Bulla M, Müller Wiefel DE, Misselwitz J, Kemper MJ: High prevalence of febrile urinary tract infections after paediatric renal transplantation. Nephrol Dial Transplant 2006, 21:3269-3274.

11. Nampoory MR, Johny KV, Costandy JN, Nair MP, Said T, Homoud H, AlMuzairai I, Samhan M, Al-Moussawi M: Infection related renal impairment: a major cause of acute allograft dysfunction. Exp Clin Transplant 2003, 1:60-64

12. Akinalolu $\mathrm{OO}$, Hanson JA, Wolfe RA, Leichtman $\mathrm{AB}$, Agodoa $\mathrm{LY}$, Lawrence YA, Port FK: Long-term survival in renal transplant recipients with graft function. Kidney Int 2000, 57:307-313.

13. Alangaden G: Urinary tract infections in renal transplant recipients. Curr Infect Dis Rep 2007, 9:475-479.

14. Sharma KK, Ayyagiri A, Dhole TN, Prasad KN, Kishore J: Prevalence of infections in renal transplant recipients of north India. Indian J Pathol Microbiol 2007, 50:453-457.

15. Valera B, Gentil MA, Cabello V, Fijo J, Cordero E, Cisneros JM: Epidemiology of urinary infections in renal transplant recipients. Transplant Proc 2006, 38:2414-2425.

16. Renoult E, Aouragh F, Mayeux D, Hestin D, Hubert J, L'Hermite J, Amicabile C, Weber M, Zerrouki-Bellou M, Blech MF, et al: Urinary tract infections during the 1st month after kidney transplantation. Agresologie 1992, 33:147-150.

17. Sharma M, Rani $\mathrm{S}$, Johnson LB: Effect of time after transplantation on microbiology of urinary tract infections among renal transplant recipients. Transpl Infect Dis 2008, 10:45-48.

18. Colombo AL, Guimãraes T: Candiduria: a clinical and therapeutic approach. Rev Soc Bras Med Trop 2007, 40:332-337.

19. Alangaden GJ, Thyagarajan R, Gruber SA, Morawski K, Garnick J, El-Amm JM West MS, Sillix DH, Chandrasekar PH, Haririan A: Clin Transplant. Infectious complications after kidney transplantation: current epidemiology and associated risk factors 2006, 20:401-409.

20. Rivera Sanchez R, Arriaga Alba M, Flores Paz R, Garcia Jimenez E: Screening method for rapid detection of bacteriuria. Enf Infec Microbiol 1997, 17:12-15. 
21. Kumar MSA, Cridge P, Molavi A, Stephan R, Abouna GM: Infectious complications in the first 100 days after renal transplantation. Transplant Proc 1995, 27(5):2705-2706.

22. Whiting P, Westwood M, Bojke L, Palmer S, Richardson G, Cooper J, Watt I, Glanville J, Sculpher M, Kleijnen J: Clinical effectiveness and costeffectiveness of test for the diagnosis and investigation of urinary tract infection in children: a systematic review and economic model. Health Technol Assess 2006, 10:1-154.

23. Kanisauskaite E, Kuzminskis V, Bumblyte IA, Maslauskiene R, Pakalnyte R: The beginning of kidney transplantation in Kaumas [results of MedicineHospital 2000-2004]. Medicina [kaunas] 2005, 41(Suppl 1):87-92.

24. Midtvedt K, Hartman A, Midtvedt T, Brekke IB: Routine perioperative antibiotic prophylaxis in renal transplantation. Nephrol Dial Transplant 1998, 13:1637-1641.

25. Dupont PJ, Psimenou E, Lord R, Buscombe JR, Hilson AJ, Sweny P: Late recurrent urinary tract infections may produce renal allograft scarring even in the absence of symptoms or vesicoureteric reflux. Transplantation 2007, 84:351-355.

26. Leigh DA: Bacteraemia in patients receiving human deceased renal transplants. J Clin Pathol 1971, 24:295-299, Sweny P: Infection and cancer following renal transplantation. Saudi J Kidney Dis Transplant 2006, 17:189199.

27. Moradi M, Abbasi M, Moradi A, Boskabadi A, Jalai A: Effect of antibiotic therapy on asymptomatic bacteriuria in kidney transplant recipients. Urol J 2005, 2(1):32-35.

28. Lazińska B, Ciszek M, Rokosz A, Sawicka-Grzelak A, Paczek L, Luczak M: Bacteriological urinalysis in patients after renal transplantation. Pol $\mathrm{J}$ Microbiol 2005, 54:317-323.

29. Kamath NS, Johon GT, Neelankantan N, Kirubakaran MG, Jacob CK: Acute graft pyelonephritis following renal transplantation. Transplant Infec Dis 2006, 8:125-127.

Pre-publication history

The pre-publication history for this paper can be accessed here: http://www.biomedcentral.com/1471-2334/10/245/prepub

\section{doi:10.1186/1471-2334-10-245}

Cite this article as: Rivera-Sanchez et al:: Prospective study of urinary tract infection surveillance after kidney transplantation. BMC Infectious Diseases 2010 10:245.

\section{Submit your next manuscript to BioMed Central and take full advantage of:}

- Convenient online submission

- Thorough peer review

- No space constraints or color figure charges

- Immediate publication on acceptance

- Inclusion in PubMed, CAS, Scopus and Google Scholar

- Research which is freely available for redistribution

Submit your manuscript at www.biomedcentral.com/submit 